\title{
Special Issues on Electrospray Ionization
}

W are witnessing a revolution in the capability of mass spectrometry to solve problems in biology and biochemistry! One major reason is electrospray ionization, which allows mass spectrometrists to use standard instrumentation to study multiply charged ions of macromolecules. Not only can molecular weights be measured, but also interactions of macromolecules with small or large molecules can be assessed. The capabilities of electrospray ionization and those of the complementary matrix-assisted laser desorption have opened the door for meaningful collaborations between mass spectrometrists and biochemists, molecular biologists, and medical researchers.

The importance of electrospray ionization was acknowledged recently by the American Society for Mass Spectrometry when John Fenn was given the 1992 Award for Distinguished Contribution in Mass Spectrometry. John is responsible for the rebirth of electrospray ionization. The editors and publisher of this journal decided that it is appropriate to dedicate two issues of JASMS to honor John and to bring to the readers a collection of articles on this subject.

This first issue is devoted to articles on theory, instrumentation, and method. We are delighted to headline the issue with an article by John Fenn.

The second issue, which will be published next month, is devoted entirely to applications of electrospray to peptide on protein chemistry. We offer our thanks to the authors and the reviewers who contributed to these special issues.

It is our hope that these two issues will find wide use not only in our community, but that of biochemists and biologists. We urge the members of the Society to share the two issues with colleagues who will benefit from the important advances that are occurring in our discipline.

Michael L. Gross Editor 